\title{
Epithelial-mesenchymal transition induced by bone morphogenetic protein 9 hinders cisplatin efficacy in ovarian cancer cells
}

\author{
YING WANG $^{1 *}$, BIN YANG $^{2 *}$, JINPING ZHAO $^{2}$, XIAOHUI YU ${ }^{1}$, XING LIU $^{1}$, LONG ZHANG $^{1}$, \\ YUNJING ZHANG $^{1}$, XIAOLI LI $^{1}$ and ZHENHUA ZHAI ${ }^{1}$ \\ ${ }^{1}$ Department of Oncology; ${ }^{2}$ Laboratory of Tumor Angiogenesis and Microenvironment, \\ The First Affiliated Hospital of Jinzhou Medical University, Jinzhou, Liaoning 121000, P.R. China
}

Received February 8, 2018; Accepted October 19, 2018

DOI: $10.3892 / \mathrm{mmr} .2019 .9814$

\begin{abstract}
Bone morphogenetic protein 9 (BMP9) belongs to the transforming growth factor- $\beta$ (TGF- $\beta$ ) superfamily, and has been reported to promote cancer cell proliferation and epithelial-mesenchymal transition (EMT). Cisplatin (DDP) is the first line treatment for ovarian cancer. However, initiation of EMT confers insensitivity to chemotherapy. The present study aimed to verify and examine the mechanisms underlying the effects of BMP9 on treatment with DDP for ovarian cancer. Prior to treatment with DDP, ovarian cancer cells were exposed to BMP9 for 3 days. Following this, cell viability, apoptosis rate and the extent of DNA damage were evaluated to compare the effects of DDP on BMP9-pretreated and non-pretreated ovarian cancer cells. In addition, EMT marker expression was evaluated by western blotting and immunofluorescence. The results demonstrated that BMP9 pretreatment inhibited the cytotoxicity of DDP on ovarian cancer cells. Additionally, BMP9-pretreated ovarian cancer cells had downregulated expression of the epithelial marker E-cadherin, which was accompanied by an upregulation of the mesenchymal markers N-cadherin, Snail, Slug, and Twist. Taken together, the findings of the present study indicated that BMP9 conferred resistance to DDP in ovarian cancer cells by inducing EMT. The present study provided valuable insight into the mechanisms of chemotherapy in
\end{abstract}

Correspondence to: Dr Zhenhua Zhai, Department of Oncology, The First Affiliated Hospital of Jinzhou Medical University, 5-2 Renmin Street, Guta, Jinzhou, Liaoning 121000, P.R. China

E-mail: zhenhua.zhai@vip.163.com

"Contributed equally

Abbreviations: EMT, epithelial-mesenchymal transition; BMPs, bone morphogenetic proteins; TGF- $\beta$, transforming growth factor- $\beta$; DDP, cisplatin

Key words: ovarian cancer, cisplatin, bone morphogenetic protein 9, EMT, chemoresistance ovarian cancer and highlighted the potential of BMP9 as a novel therapeutic target for improving cisplatin chemosensitivity.

\section{Introduction}

Ovarian cancer is a major health concern in women. It has been reported to be the leading cause of cancer-associated mortality in females worldwide and in the Chinese population. Approximately 251,000 (239,000-266,000) cases and 161,000 (157,000-167,000) mortalities caused by ovarian cancer were reported in China in $2015(1,2)$. Efficient therapeutic regimens partly suppress the growth of tumors; however, chemotherapy resistance significantly reduces treatment efficacy $(3,4)$. Current research has primarily focused on increasing the effectiveness of chemotherapy. Cisplatin (DDP) and its analogues currently serve as the first line chemotherapy for the treatment of ovarian cancer (5). DDP exerts cytotoxic effects and triggers apoptosis in cancer cells by forming DNA-protein cross-links, which leads to breakage of DNA strands (6). However, chemoresistance to DDP has been proven to limit successful treatment outcomes for ovarian cancer (7).

In the tumor microenvironment, extracellular molecules for transducing signals and establishing connections between cancer cells and stromal cells have gained increasing attention in research (8). Transforming growth factor- $\beta$ (TGF- $\beta$ ) functions as an extracellular signaling ligand by binding to transmembrane type I and II serine/threonine kinase receptors (9), and has been extensively investigated due to its role in tumorigenesis and cancer progression $(9,10)$. TGF- $\beta$ has been reported to serve as a tumor suppressor in premalignant samples, and is additionally known to serve as a tumor promoter during the advanced stages of cancer development (10). Furthermore, TGF- $\beta$ has been demonstrated to be involved in cancer cell chemoresistance by inducing epithelial-mesenchymal transition (EMT) (11-13). However, there is limited knowledge on the function of bone morphogenetic proteins (BMPs), which are members of TGF- $\beta$ superfamily, in tumor progression and treatment (9).

Previous studies have reported the effects of BMPs on cancer progression, and BMP signaling has gained increasing 
attention in research because of its dual role as a tumor suppressor and promoter (14-17). Furthermore, overexpression of BMPs has been detected in a number of tumor types, including non-small cell lung carcinoma, prostate, ovarian and gastric cancer (18). Notably, BMP signaling has been demonstrated to be crucial to the development and function of normal ovarian cells (19). In addition, BMPs were demonstrated to exert proliferative effects on ovarian cancer cells $(20,21)$.

BMP9, additionally termed growth differentiation factor 2, belongs to the BMP family of proteins and is involved in glucose homeostasis, angiogenesis and tumor progression (22-24). During ovarian cancer progression, BMP9 has been proposed to exert dual functions as a tumor promoter and suppressor (25-27). In a recent study, BMP9 was reported to promote cell growth in ovarian cancer cells (20). However, how the proliferative or other effects of BMP9 affect the efficacy of DDP chemotherapy during the treatment of ovarian cancer remains unknown. In the present study, the role of BMP9 in the treatment of ovarian cancer with DDP and the mechanisms underlying the effects of BMP9 were investigated.

\section{Materials and methods}

Cell culture. Human ovarian cancer cell lines HO8910 (National Infrastructure of Cell Line Resource, Beijing, China) and SKOV3 (National Science \& Technology Infrastructure) were cultured in Dulbecco's modified Eagle's medium (Corning Inc., Corning, NY, USA) containing 10\% fetal bovine serum (Thermo Fisher Scientific, Inc., Waltham, MA, USA) and $1 \%$ penicillin-streptomycin (cat. no. PS2004HY; Tianjin HaoYang Biological Manufacture Co., Ltd., Tianjin, China), at $37^{\circ} \mathrm{C}$ in a humidified atmosphere containing $5 \% \mathrm{CO}_{2}$. Trypsin-EDTA $(0.25 \%$; cat. no. TE2004Y; Tianjin HaoYang Biological Manufacture Co., Ltd.) was used to detach the cells.

MTT assay. HO8910 (1×10 cells $/ \mathrm{ml})$ and SKOV3 $\left(2 \times 10^{4} / \mathrm{ml}\right)$ cells in $100 \mu 1$ culture medium were seeded into 96 -well plates and treated with BMP9 $(0,1,3,5$ and $10 \mathrm{ng} / \mathrm{ml}$; cat. no. 120-07; PeproTech, Inc., Rocky Hill, NJ, USA) and DDP $(0,1.25,2.5,5,10$ and $20 \mu \mathrm{g} / \mathrm{ml}$; Jiangsu Hansoh Pharmaceutical Co., Ltd., Jiangsu, China) for 24, 48 and $72 \mathrm{~h}$, or pretreated with BMP9 $(0,1,3,5$ and $10 \mathrm{ng} / \mathrm{ml})$ for $72 \mathrm{~h}$ and subsequently treated with DDP $(0,1.25,2.5,5,10$ and $20 \mu \mathrm{g} / \mathrm{ml})$. Following this, $10 \mu \mathrm{l}$ MTT reagent $(5 \mathrm{mg} / \mathrm{ml}$ in PBS) was incubated with cells for $4 \mathrm{~h}$. The supernatant was subsequently removed and $100 \mu \mathrm{l}$ dimethyl sulfoxide was added to dissolve the formazan product. Finally, the absorbance was measured at $490 \mathrm{~nm}$ using a microplate reader and the optical density (OD) values were analyzed. The inhibitory effects of DDP were calculated as: OD value (without treatment of DDP)-OD value (DDP treatment)/OD value (without treatment of DDP) in the MTT assay. Each experiment was performed three times.

Flow cytometry. For analysis of cell apoptosis, HO8910 and SKOV3 cells were seeded into six-well plates at a density of $5 \times 10^{4}$ cells/well. Cells were incubated with BMP9 $(5 \mathrm{ng} / \mathrm{ml})$ for $3 \mathrm{~h}$ and subsequently treated with DDP for a further $72 \mathrm{~h}$. Cells were subsequently collected, washed with cold PBS, suspended in $1 \mathrm{X}$ binding buffer, and incubated with fluorescent dyes according to the staining protocol provided in the Annexin V-FITC (7-AAD) apoptosis analysis kit (cat. no. AO2001-02A; Tianjin Sungene Biotech Co., Ltd., Tianjin, China). Finally, the cells were subjected to a fluorescence-activated cell sorting assay and analyzed using FlowJo software (version 7.6; Tree Star, Inc., Ashland, OR, USA).

Alkaline comet assay. Cells were subjected to an Alkaline comet assay using a comet assay kit (cat. no. 4250-050-K; Trevigen, Inc.; Gaithersburg, MD, USA) according to the manufacturer's protocol. In total, $12 \mu 110^{4}$ cells $/ \mathrm{ml}$ were mixed with $120 \mu \mathrm{l}$ low-melting agarose at a ratio of 1:10. Subsequently, $50 \mu 1$ of the resulting mixture was immediately spread on a CometSlide ${ }^{\mathrm{TM}}$, provided in the comet assay kit; the slides were incubated at $4^{\circ} \mathrm{C}$ in a dark and humid environment. After $40 \mathrm{~min}$, the slides were immersed in $4^{\circ} \mathrm{C}$ lysis buffer, additionally provided in the kit, for $30 \mathrm{~min}$. Subsequently, the slides were coated with mixture of cells, and gels were immersed in DNA unwinding solution (mixture of $0.4 \mathrm{~g}$ $\mathrm{NaOH}, 250 \mu 1200 \mathrm{mM}$ EDTA and $49.75 \mathrm{ml}$ distilled water) at room temperature for $30 \mathrm{~min}$. Subsequently, the slides were resolved via electrophoresis at $21 \mathrm{~V}$ and $4^{\circ} \mathrm{C}$ for $30 \mathrm{~min}$, and fixed in $70 \%$ ethanol at room temperature for $5 \mathrm{~min}$. Samples were subsequently dried at $37^{\circ} \mathrm{C}$ for $1 \mathrm{~h}$ and stained with SYBR-Green I (Beijing Dingguo Changsheng Biotechnology Co., Ltd., Beijing, China) in the dark at room temperature for $30 \mathrm{~min}$. At least three images in each slide were captured via fluorescence microscopy (Olympus Corporation, Tokyo, Japan; magnification, x200), and analyzed using Comet Score software (version 1.5; TriTek Solutions, Inc., Rancho Santa Margarita, CA, USA). According to the manufacturer's protocol, the extent of DNA damage is proportional to the amount and length of the DNA fragments in the comet tail. Tail moment is a damage measure that combines the amount of DNA in the comet tail with the distance of migration. The tail moment and the percent tail DNA in the comet tail (\% tail DNA) represented the degree of DNA damage.

Western blot analysis. A total of $5 \times 10^{5}$ cells were seeded in $100 \mathrm{~mm}$ dishes and treated with BMP9 $(0,1,3,5$ and $10 \mathrm{ng} / \mathrm{ml})$ for $72 \mathrm{~h}$. Cells were subsequently lysed in radioimmunoprecipitation assay buffer (cat. no. P0013B; Beyotime Institute of Biotechnology, Shanghai, China) for isolation of protein. Total proteins $(80 \mu \mathrm{g} / \mathrm{lane})$, which were determined by a bicinchoninic acid assay (cat. no. P0011; Beyotime Institute of Biotechnology), were separated by 8 or $12 \%$ SDS-PAGE and transferred to polyvinylidene fluoride membranes (PVDF; EMD Millipore, Billerica, MA, USA). Following this, PVDF membranes were blocked with 5\% non-fat milk at room temperature for $1 \mathrm{~h}$ and incubated with the following primary antibodies overnight at $4^{\circ} \mathrm{C}$ : Anti-E-cadherin (dilution, 1:1,000; cat. no. 208741-1-AP; ProteinTech Group, Inc., Chicago, IL, USA), anti-N-cadherin (dilution, 1:1,000; cat. no. 610920; BD Biosciences, Franklin Lakes, NJ, USA), anti-zinc finger protein SNAI1 (Snail; dilution, 1:1,000; cat. no. 3895s; Cell Signaling Technology, Inc., Danvers, MA, USA), anti-zinc finger protein SNAI2 (Slug; dilution, 1:500; cat. no. WL01508; Wanleibio Co., Ltd., Shanghai, China), 
anti-twist-related protein 1 (Twist; dilution, 1:500; cat. no. WL0109; Wanleibio Co., Ltd.) and anti- $\beta$-actin (dilution, 1:5,000; cat. no. HC201-01; Beijing TransGen Biotech Co., Ltd., Beijing, China). Samples were subsequently incubated with goat anti-mouse or goat anti-rabbit secondary antibody conjugated with horseradish peroxidase (dilution, 1:2,000; cat. nos. 7076 and 7077; Cell Signaling Technology, Inc.) at room temperature for $1 \mathrm{~h}$. Protein expression levels were evaluated on a chemiluminescent imaging system (LAS4010; GE Healthcare Bio-Sciences, Pittsburgh, PA, USA) following exposure to electrochemiluminescence reagent (Beijing TransGen Biotech Co., Ltd.). Gray values of protein bands were analyzed using ImageJ software (version Java 1.6.0_20; National Institutes of Health, Bethesda, MD, USA).

Immunofluorescence assay. A total of 5,000 cells/well were cultured in 8-well chamber slides and treated with BMP9 $(0,1,3,5$ and $10 \mathrm{ng} / \mathrm{ml})$ for $72 \mathrm{~h}$. Following this, samples were fixed in $4 \%$ paraformaldehyde for $5 \mathrm{~min}$ at room temperature and incubated with $5 \%$ bovine serum albumin (cat. no. A8020; Beijing Solarbio Science \& Technology Co., Ltd.; Shanghai, China). Subsequently, the samples were incubated with anti-E-cadherin (dilution, 1:1,000) and mouse anti-N-cadherin (dilution, 1:1,000) primary antibodies overnight at $4^{\circ} \mathrm{C}$. Samples were subsequently incubated with Alexa Fluor 594-conjugated goat anti-rabbit (dilution, 1:200; cat. no. A-11005; Thermo Fisher Scientific, Inc.), and Alexa Fluor 488-conjugated goat anti-mouse (dilution, 1:200; cat. no. A-11008; Thermo Fisher Scientific, Inc.) secondary antibodies at room temperature for $1 \mathrm{~h}$. ProLong ${ }^{\mathrm{TM}}$ Gold Antifade Mountant with DAPI was used to counterstain the nuclei (cat. no. P36931; Invitrogen; Thermo Fisher Scientific, Inc.). Images of stained cells were acquired using a fluorescent microscope (Axio Imager M2; Zeiss GmbH, Jena, Germany; magnification, x200).

Statistical analysis. JMP software (version 11; SAS Institute, Inc., Cary, NC, USA) was used for statistical analysis. For comparing normally distributed data among multiple groups, one-way analysis of variance followed by the Tukey-Kramer method were used to analyze differences between groups. The data are presented as the mean \pm standard deviation. Each experiment was conducted at least three times. $\mathrm{P}<0.05$ was considered to indicate a statistically significant difference.

\section{Results}

BMP9 enhances the chemoresistance of ovarian cancer cells to DDP. To verify the effects of BMP9 on the efficacy of DDP in ovarian cancer treatment, ovarian cancer cell lines (SKOV3 and HO8910) were separately treated with BMP9 (Fig. 1A and B) or DDP (Fig. 1C and D), and in combination (Fig. 1E and F). Cell morphology was not notably altered following incubation with BMP9 (Fig. $1 \mathrm{G}$ and H). Results of the MTT assay revealed no statistically significant differences among the OD values of ovarian cancer cells treated with BMP9 $(0,1,3,5$, and $10 \mathrm{ng} / \mathrm{ml})$ for 24, 48 and $72 \mathrm{~h}$, which indicated that BMP9 did not significantly affect the ovarian cancer cell viability (Fig. 1A and B). However, the OD values of ovarian cancer cells pretreated with BMP9 (5 and $10 \mathrm{ng} / \mathrm{ml})$ for $72 \mathrm{~h}$ and subsequently treated with DDP for a further $72 \mathrm{~h}$ were higher than those of non-pretreated cells. On the other hand, BMP9 did not blunt the cytotoxicity of DDP at concentrations of $>5 \mu \mathrm{g} / \mathrm{ml}$ (Fig. 1C and D). At a concentration of $10 \mu \mathrm{g} / \mathrm{ml}$, the inhibitory effects of treatment with DDP for $72 \mathrm{~h}$ were significant, with inhibition ratios of $0.95 \pm 0.003$ in H08910 cells and $0.93 \pm 0.01$ in SKOV3 cells (Fig. 1C and D). These results indicated that BMP9 partially counteracted the effects of DDP in ovarian cancer cells, and that these effects were not caused by increased cell viability.

BMP9 reduces DDP efficacy by attenuating DNA damage. DDP triggers apoptosis in cancer cells by forming cross-links within DNA double strands, thereby leading to DNA breakage and the generation of cleaved DNA fragments (28). The cytotoxic effect of DDP on SKOV3 was greater compared with HO8910. Upon treatment with $1.25 \mu \mathrm{g} / \mathrm{ml}$ DDP for $72 \mathrm{~h}$, the inhibitory effect of DDP on HO8910 was $0.57 \pm 0.01$ (Fig. 1C), and the inhibitory effect of DDP on SKOV3 was $0.86 \pm 0.01$ (Fig. 1D), which was considered too severe. Therefore, the HO8910 cell line was selected to evaluate the effects of BMP9 on DNA damage. An alkaline comet assay was conducted to evaluate the effects of BMP9 $(5 \mathrm{ng} / \mathrm{ml})$ on DDP-induced DNA damage in HO8910 cells $(1.25$ and $2.5 \mu \mathrm{g} / \mathrm{ml})$. Untreated cells were used as the control group. The results demonstrated that BMP9 treatment reduced DNA quantity in the tail moment, and the $\%$ tail DNA caused by DDP in HO8910 cells (Fig. 2A-C). Without considering the distance of migration, $\%$ tail DNA is a normalized measure of the percent of total cell DNA found in the tail. The above results indicated that exposure to BMP9 prior to DDP treatment enhanced ovarian cancer cell chemoresistance.

The apoptosis assay further confirmed the influence of BMP9 on the apoptotic effects of DDP in HO8910 cells. Consistent with the results of the comet assay, BMP9 $(5 \mathrm{ng} / \mathrm{ml})$ decreased the apoptotic rate of HO8910 cells treated with DDP at 1.25 and $2.5 \mu \mathrm{g} / \mathrm{ml}$ (Fig. 2D). Therefore, it was concluded that BMP9 treatment reduced DDP-induced DNA damage and subsequently inhibited apoptosis in ovarian cancer cells.

BMP9 induces EMT in ovarian cancer cells. EMT has been demonstrated to act as the primary mechanism responsible for chemoresistance during cancer treatment (11). Therefore, whether BMP9-induced resistance to DDP was associated with EMT was investigated. Following BMP9 treatment $(0,1,3,5$ and $10 \mathrm{ng} / \mathrm{ml})$, morphological alterations were not notable in HO8910 and SKOV3 cells. In addition, the protein expression levels of EMT markers, including E-cadherin, $\mathrm{N}$-cadherin, and Snail were detected via western blotting and immunofluorescence analysis in HO8910 and SKOV3 cells (Fig. 3). The results revealed that BMP9 treatment $(0,1$, 3,5 and $10 \mathrm{ng} / \mathrm{ml}$ ) downregulated the expression of epithelial marker E-cadherin and upregulated the expression of mesenchymal markers N-cadherin, Snail, Slug and Twist in a dose-dependent manner. The above findings demonstrated that BMP9 may promote EMT in ovarian cancer cells, which may partially explain BMP9-induced DDP chemoresistance. 

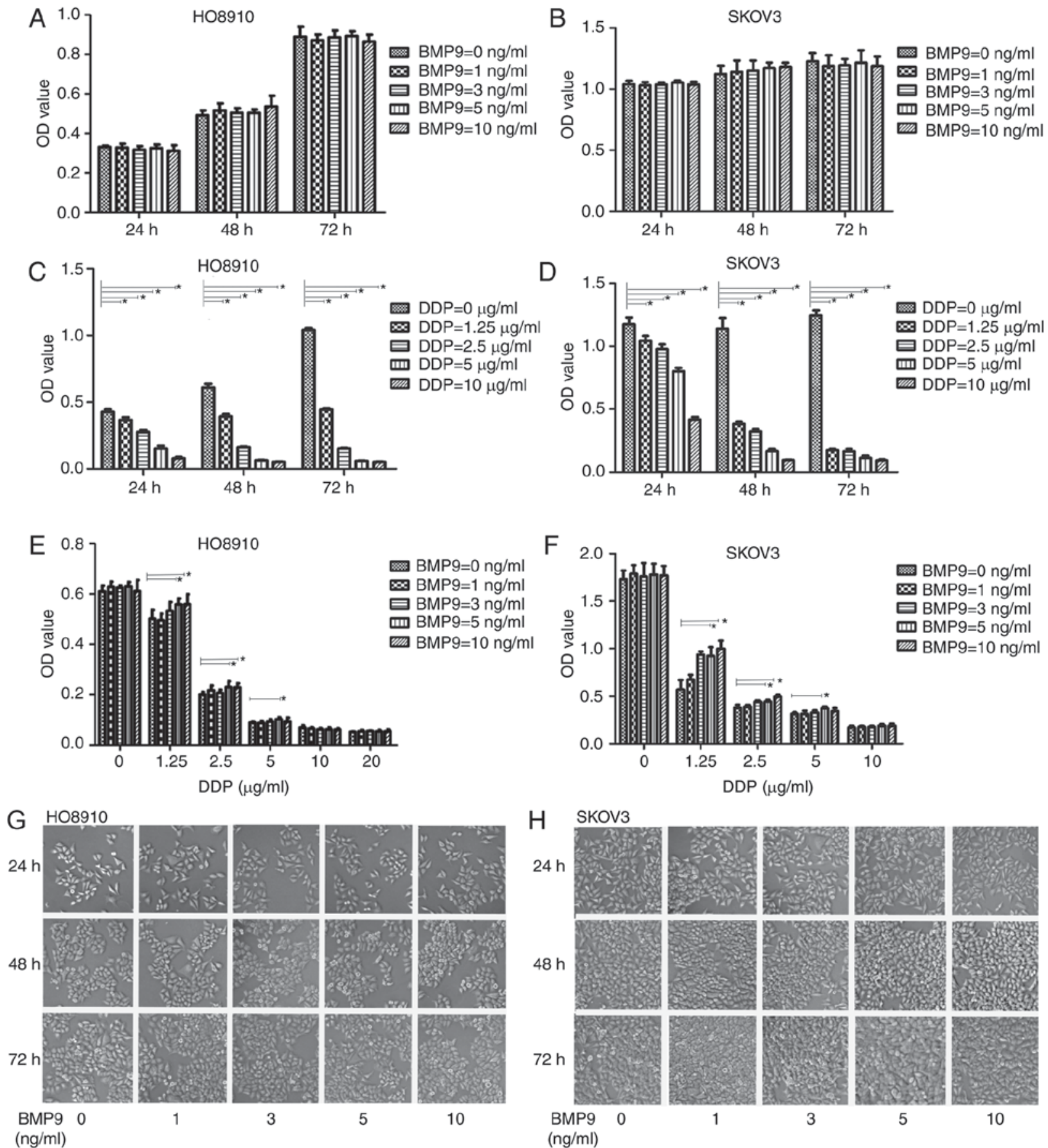

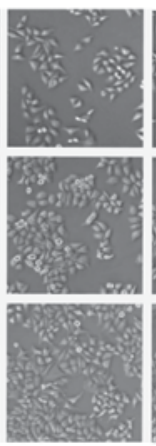

5
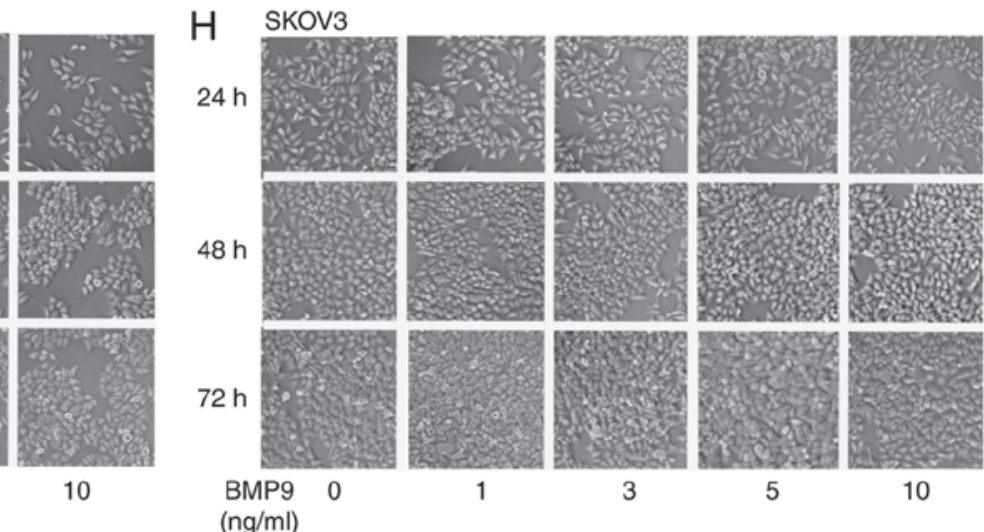

$(\mathrm{ng} / \mathrm{ml})$
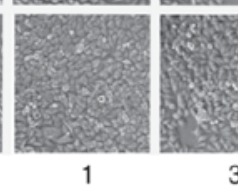

3

BMP9=0 $\mathrm{ng} / \mathrm{ml}$ $\triangle \mathrm{BMPg}=1 \mathrm{ng} / \mathrm{ml}$ В BMP9=3 $\mathrm{ng} / \mathrm{ml}$ 四 $\mathrm{BMP9}=5 \mathrm{ng} / \mathrm{ml}$ mMP9 $=10 \mathrm{ng} / \mathrm{ml}$

Figure 1. BMP9 decreases the cytotoxic effects of DDP on ovarian cancer cells. Cell viability of (A) HO8910 and (B) SKOV3 cells following treatment with BMP9. Cell viability of (C) HO8910 and (D) SKOV3 cells following DDP exposure. Cell viability of (E) HO8910 and (F) SKOV3 cells following treatment with DDP for $72 \mathrm{~h}$ with or without BMP9 pretreatment for $72 \mathrm{~h}$. Representative images of $(\mathrm{G})$ HO8910 and (H) SKOV3 cell morphology following incubation with BMP9 for 24, 48 and $72 \mathrm{~h}$. "P<0.05. OD, optical density; BMP9, bone morphogenetic protein 9; DDP, cisplatin.

\section{Discussion}

DDP is an important drug that is widely used for chemotherapy in ovarian cancer (5). However, the efficiency of DDP is significantly limited by the development of resistance during therapy. BMP ligands are extracellular molecules that are secreted by cancer and stromal cells into the tumor microenvironment, that exert their effects on ovarian cancer cells by binding to transmembrane receptors (20). In the present study, BMP9 was demonstrated to reduce the cytotoxic and apoptotic effects of DDP on ovarian cancer cells. In addition, BMP9 treatment reduced DDP-induced
DNA damage. These results demonstrated that BMP9 enhanced the resistance of ovarian cancer cells to DDP.

The association between BMPs and drug resistance during chemotherapy has been previously reported in esophageal carcinoma (29). Treatment with TGF- $\beta$ and BMP signaling pathway inhibitors has been reported to enhance the antitumor effects of DDP in cancer cells $(30,31)$. Additionally, other members of the BMP family, such as BMP6, have been implicated as negative chemoresistance-associated factors (32). However, the effects of BMP6 were evaluated based on protein expression in cancer cells (32), and not as a ligand. The results indicated that BMP 
A
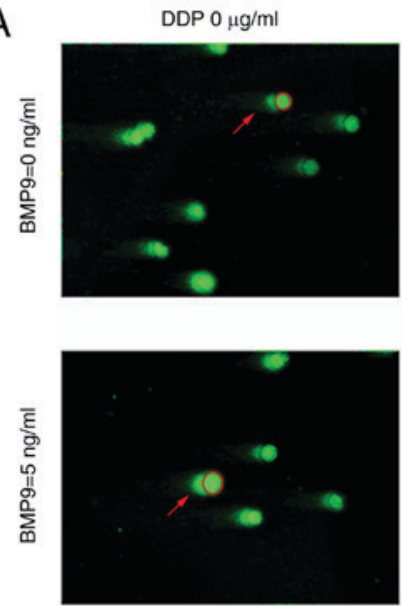

B

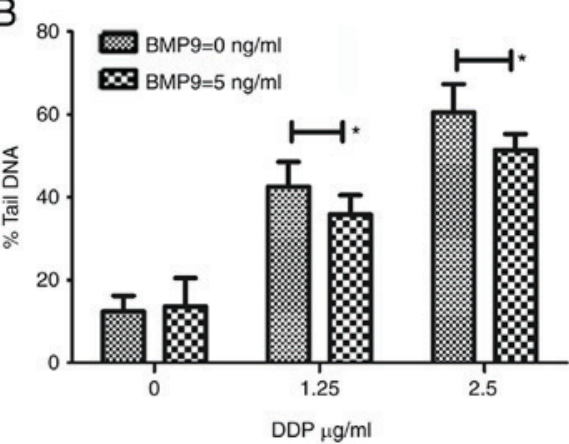

C

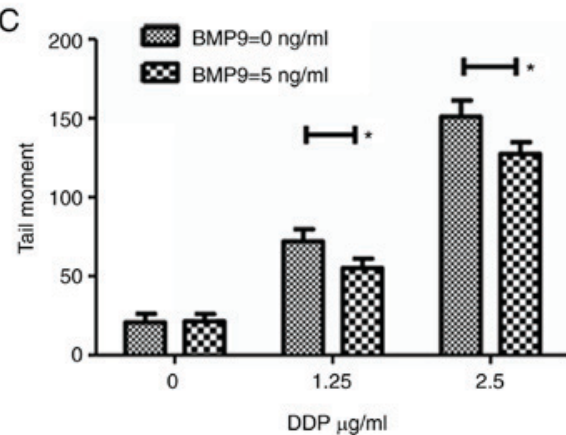

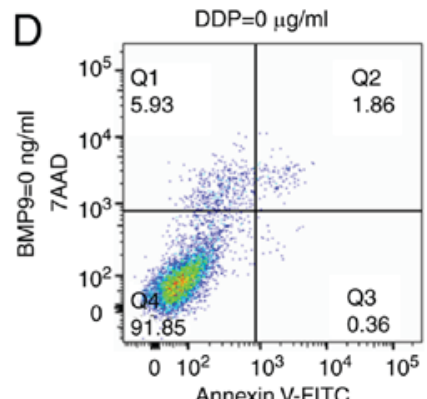
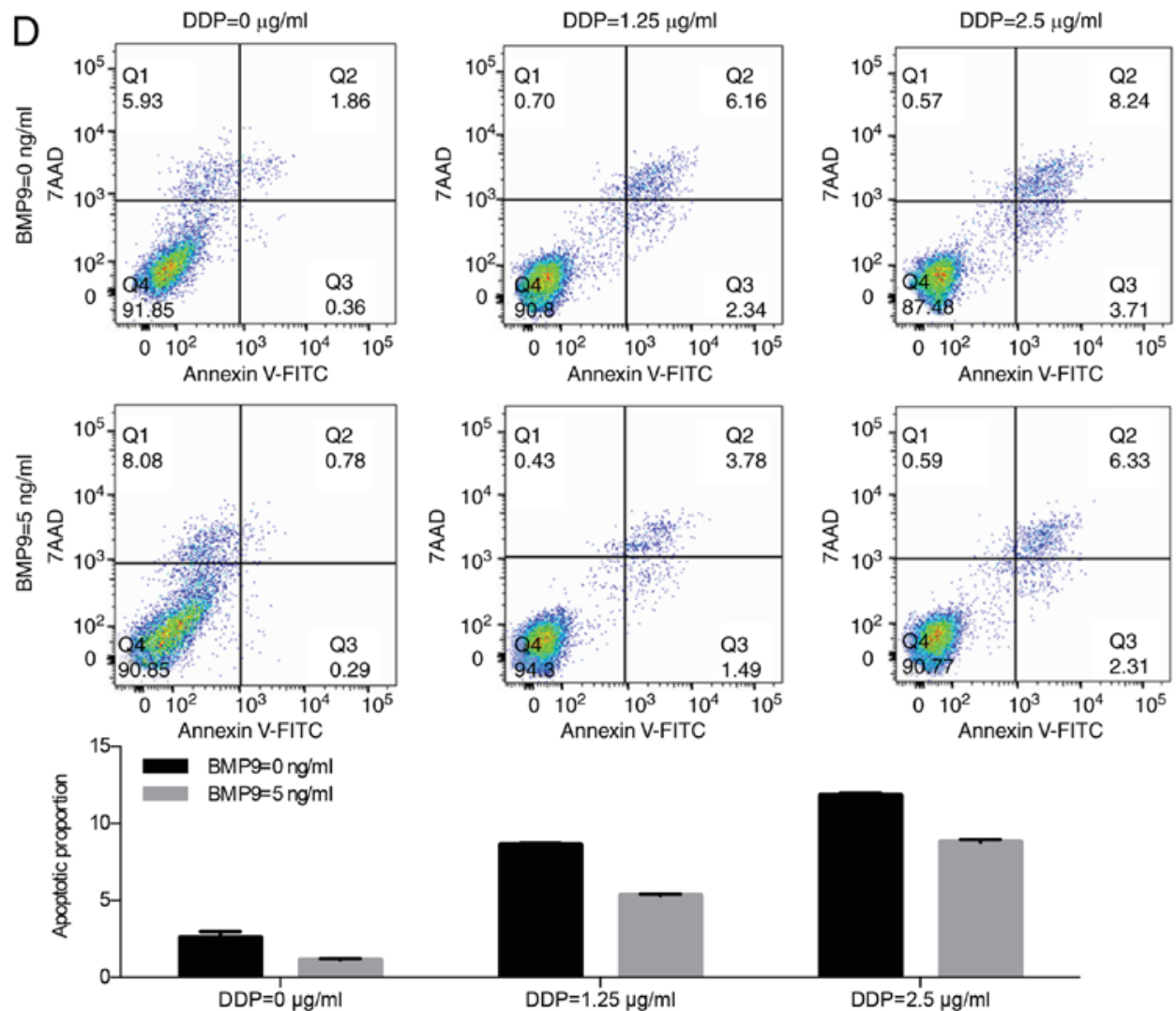

Figure 2. DDP-induced DNA damage and apoptosis are partly counteracted by BMP9. (A) Representative images of DNA damage following DDP treatment for $72 \mathrm{~h}$ with or without BMP9 pretreatment for $72 \mathrm{~h}$. (B) \% Tail DNA and (C) tail moment are presented to depict the degree of DDP-induced DNA damage. Tail Moment is a damage measure combining the amount of DNA in the comet tail with distance of migration. \%Tail DNA was calculated as the percentage of DNA in the tail compared to the total amount of DNA, without considering the distance of migration. Red circles indicate DNA in the nucleus, and red arrows indicate cleaved DNA fragments pulled out of the nucleus. At least three fields in each slide were assessed to obtain this quantification. (D) DDP-induced apoptosis (percentage of Q2 plus Q3) was inhibited by BMP9 treatment at a concentration of $5 \mathrm{ng} / \mathrm{ml}$. * $\mathrm{P}<0.05$. DDP, cisplatin; BMP9, bone morphogenetic protein 9; Q, quadrant; 7-AAD, 7-aminoactinomycin D; FITC, fluorescein isothiocyanate. 
A

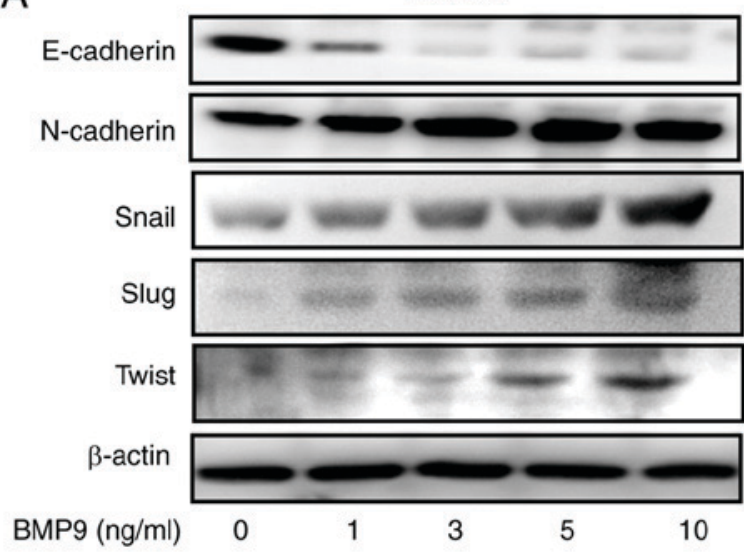

B

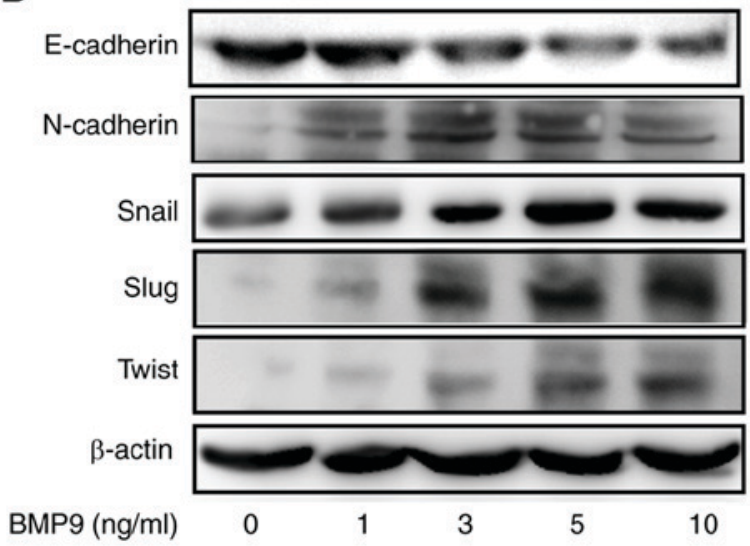

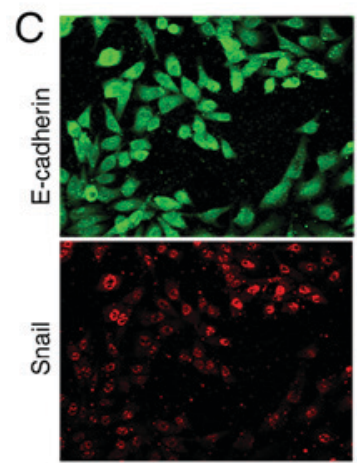

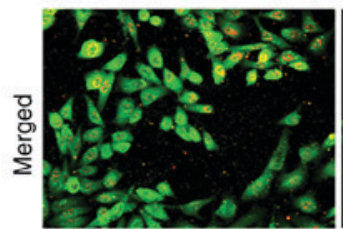

BMP9

$(\mathrm{ng} / \mathrm{ml})$
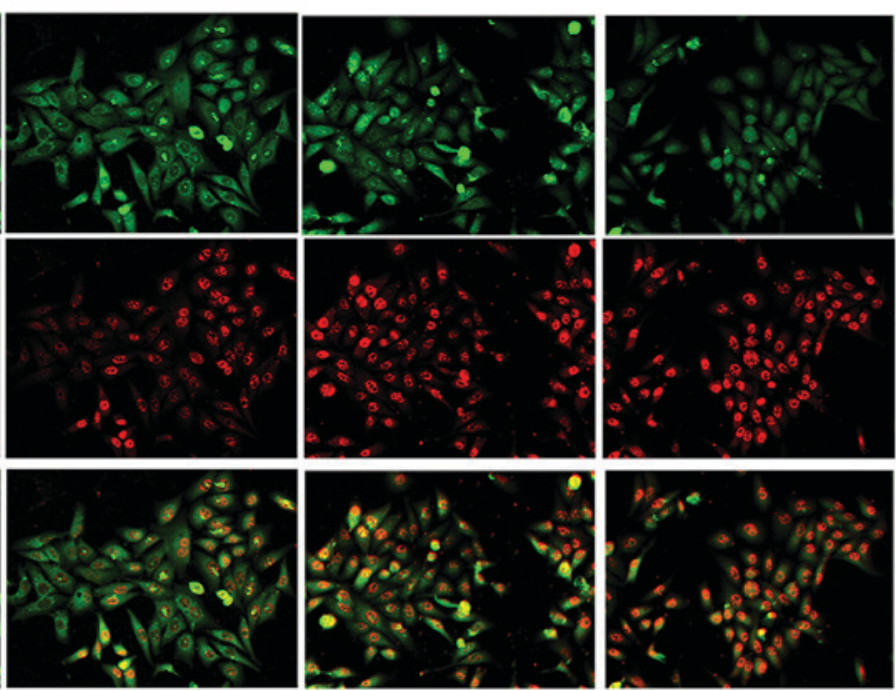

1

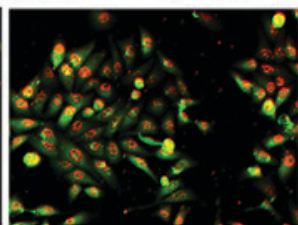

3

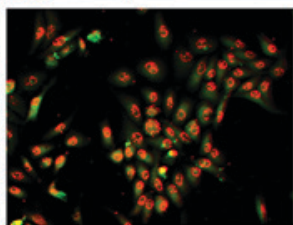

5

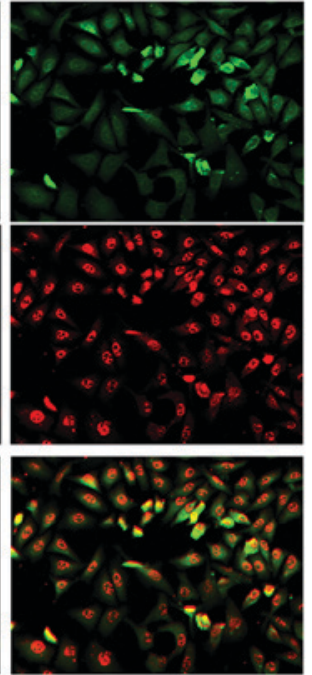

10

Figure 3. BMP9-induced epithelial-mesenchymal transition in ovarian cancer cells. Representative results depicting the protein expression levels of an epithelial marker (E-cadherin) and mesenchymal markers (N-cadherin, Snail, Slug and Twist) following treatment with BMP9 for 3 days in (A) HO8910 and (B) SKOV3 cells. (C) Immunofluorescence images of labeled epithelial marker (E-cadherin) and mesenchymal marker (Snail) following incubation of HO8910 cells with BMP9 for 3 days. Snail, zinc finger protein SNAI1; Slug, zinc finger protein SNAI2; Twist, twist-related protein 1; BMP9, bone morphogenetic protein 9.

ligands function independently of BMP expression in cancer cells. Therefore, the effects of BMPs during cancer treatment are versatile and require further examination.

Previous studies have demonstrated that BMPs, including BMP2 and BMP9, promote the growth of ovarian cancer cells $(20,33)$. Therefore, the present study aimed to investigate whether the proliferative effects of BMP9 influenced the response of ovarian cancer cells to DDP. Notably, the results indicated that BMP9-mediated DDP resistance was independent of the proliferative effects of BMP9. Ovarian cancer cell viability remained unchanged following exposure to BMP9 when compared to the negative controls, concomitant with decreased sensitivity to DDP. The above results indicated that the drug resistance mechanisms in ovarian cancer cells were largely caused by an indirect effect on other malignant phenotypes, excluding proliferation. The observed non-proliferative effects of BMP9 appeared to be inconsistent with the results of a previous study indicating that BMP9 serves as a proliferative factor in ovarian cancer cells; the ovarian cancer cells were exposed to serum-free medium containing BMP (33). This suggested that
BMP9-induced proliferation may be masked by physiologically relevant concentrations of serum-derived BMP9 (33). In the present study, ovarian cancer cells were cultured in medium containing serum that promoted the proliferative environment to mimic the growth of ovarian cancer in vivo. Therefore, the proliferative effect of BMP9 cannot be excluded as an antagonistic mechanism against DDP in the treatment of ovarian cancer cells. However, the results of the present study indicated that BMP9-induced EMT serves a more important role in chemoresistance.

BMP9 has been demonstrated to induce EMT, promote the migration and increase the growth of cancer cells in hepatocellular and renal carcinoma $(26,34)$. Furthermore, EMT has been associated with resistance to platinum-based chemotherapy (11). Thus, it was hypothesized that BMP9 may also induce EMT in ovarian cancer cells, thus leading to chemoresistance to DDP. Alterations in the expression of epithelial and mesenchymal markers in BMP9-treated ovarian cancer cells were examined. The results demonstrated that BMP9 downregulated the expression of E-cadherin 
and upregulated the expression of N-cadherin, Snail, Slug and Twist. These results indicated that BMP9 induced EMT in ovarian cancer cells. Additionally, in the present study, cells treated with BMP9 exhibited both upregulated mesenchymal-specific markers and downregulated epithelial markers, but cell morphology had not been altered. Such cells without spindle-shaped morphology are likely to represent the intermediate stage of EMT, when epithelial markers continue to be expressed but new mesenchymal markers have already been acquired (35). Although BMPs are dependent of the canonical mothers against decapentaplegic homolog (SMAD) signaling pathway, they also interact with non-SMAD signaling pathways, including the Ras/RAF/mitogen-activated protein kinase and phosphoinositide 3-kinase/protein kinase B pathways, which may be induced by gene alterations, including BRAF, KRAS or PTEN, and are involved in triggering EMT $(36,37)$. However, the cross talk between mutation-activated signaling with EMT and BMP9 signaling pathways remains to be elucidated.

EMT is known to promote the aggressiveness of ovarian cancer cells (38) and also to contribute to chemoresistance during treatment (39). In addition, patients with ovarian cancer subjected to platinum-based chemotherapy were reported exhibit and increase in EMT-like circulating tumor cells (40). Recently, EMT has been suggested to cause an increased in the cancer stem cell-like properties of cancer cells, which in turn further increases resistance to chemotherapy (41). In addition, Snail confers resistance to cell death induced by pro-apoptotic signals (42). Previous studies have successfully restored the cytotoxic effects of chemotherapy by inhibiting EMT (43). Taken together, these previous studies and the findings of the present study indicated that BMP9-induced EMT contributes to DPP resistance in ovarian cancer cells, and BMP9 antagonism may enhance the sensitivity of ovarian cancer cells to DDP, which would potentially benefit patients who have developed resistance to DDP treatment.

In addition, EMT may lead to chemoresistance against many drugs (41); the present study only evaluated the effects of BMP-induced EMT on DDP resistance. Subsequent studies should be extended to other drugs, including carboplatin, paclitaxel and docetaxel, which are involved in routine clinical adjuvant treatment. Taken together, the findings of the current study indicated that BMP9 may be useful in reducing acquired resistance to DDP during chemotherapy in ovarian cancer. These findings have important implications for preventing the development of chemoresistance during treatment against ovarian cancer.

\section{Acknowledgements}

The authors would like to thank Dr Yuanyuan Wang (Department of Oncology, The First Affiliated Hospital of Jinzhou Medical University, Jinzhou, China) for analyzing the flow cytometry results.

\section{Funding}

The present study was supported by Scientific Research Starting Foundation of the Affiliated Hospital of Jinzhou Medical University (grant no. FYK201202; Jinzhou, China).

\section{Availability of data and materials}

The datasets used and/or analysed during the current study are available from the corresponding author on reasonable request.

\section{Authors' contributions}

YW and BY contributed to the conception and design of the study, acquired and analyzed the data, and drafted the manuscript. JZ, XY, XL, LZ, YZ and XLL contributed to the design of the study, acquired and analyzed the data, and revised the manuscript. $\mathrm{ZZ}$ contributed to the conception and design of the study, acquired and analyzed the data, and revised the article critically for important intellectual content. All authors read and approved the final manuscript.

\section{Ethics approval and consent to participate}

Not applicable.

\section{Patient consent for publication}

Not applicable.

\section{Competing interests}

The authors declare that they have no competing interests.

\section{References}

1. Chen W, Zheng R, Baade PD, Zhang S, Zeng H, Bray F, Jemal A, Yu XQ and He J: Cancer statistics in China, 2015. CA Cancer J Clin 66: 115-132, 2016.

2. Global Burden of Disease Cancer Collaboration, Fitzmaurice C, Allen C, Barber RM, Barregard L, Bhutta ZA, Brenner H, Dicker DJ, Chimed-Orchir O, Dandona R, et al: Global, regional, and national cancer incidence, mortality, years of life lost, years lived with disability, and disability-adjusted life-years for 32 cancer groups, 1990 to 2015: A systematic analysis for the global burden of disease study. JAMA Oncol 3: 524-548, 2017.

3. Zhao H, Wei W, Sun Y, Gao J, Wang Q and Zheng J: Interference with the expression of $\beta$-catenin reverses cisplatin resistance in A2780/DDP cells and inhibits the progression of ovarian cancer in mouse model. DNA Cell Biol 34: 55-62, 2015.

4. Morgan SL, Medina JE, Taylor MM and Dinulescu DM: Targeting platinum resistant disease in ovarian cancer. Curr Med Chem 21: 3009-3020, 2014

5. Ye H, Karim AA and Loh XJ: Current treatment options and drug delivery systems as potential therapeutic agents for ovarian cancer: A review. Mater Sci Eng C Mater Biol Appl 45: 609-619, 2014.

6. McKeage MJ: New-generation platinum drugs in the treatment of cisplatin-resistant cancers. Expert Opin Investig Drugs 14: 1033-1046, 2005

7. Yu X, Chen Y, Tian R, Li J, Li H, Lv T and Yao Q: miRNA-21 enhances chemoresistance to cisplatin in epithelial ovarian cancer by negatively regulating PTEN. Oncol Lett 14: 1807-1810, 2017.

8. Quail DF and Joyce JA: Microenvironmental regulation of tumor progression and metastasis. Nat Med 19: 1423-1437, 2013.

9. Pickup M, Novitskiy S and Moses HL: The roles of TGF $\beta$ in the tumour microenvironment. Nat Rev Cancer 13: 788-799, 2013.

10. Wakefield LM and Hill CS: Beyond TGF $\beta$ : Roles of other TGFbeta superfamily members in cancer. Nat Rev Cancer 13: 328-341, 2013.

11. Marchini S, Fruscio R, Clivio L, Beltrame L, Porcu L, Fuso Nerini I, Cavalieri D, Chiorino G, Cattoretti G, Mangioni C, et al: Resistance to platinum-based chemotherapy is associated with epithelial to mesenchymal transition in epithelial ovarian cancer. Eur J Cancer 49: 520-530, 2013. 
12. Liang S, Marti TM, Dorn P, Froment L, Hall S, Berezowska S, Kocher G, SchmidRA and Peng R: 18P-Epithelial-to-mesenchymal transition (EMT) is required for resistance to anti-folate chemotherapy in lung cancer. J Thor Onc 11: S63, 2016.

13. Funaki S, Shintani Y, Kawamura T, Kanzaki R, Minami M and Okumura M: Chemotherapy enhances programmed cell death 1/ligand 1 expression via TGF- $\beta$ induced epithelial mesenchymal transition in non-small cell lung cancer. Oncol Rep 38 : 2277-2284, 2017

14. Ma W, Ma J, Xu J, Qiao C, Branscum A, Cardenas A, Baron AT, Schwartz P, Maihle NJ and Huang Y: Lin28 regulates BMP4 and functions with Oct4 to affect ovarian tumor microenvironment. Cell Cycle 12: 88-97, 2013.

15. Ehata S, Yokoyama Y, Takahashi K and Miyazono K: Bi-directional roles of bone morphogenetic proteins in cancer: Another molecular Jekyll and Hyde? Pathol Int 63: 287-296, 2013

16. Wang K, Feng H, Ren W, Sun X, Luo J, Tang M, Zhou L, Weng Y, He TC and Zhang Y: BMP9 inhibits the proliferation and invasiveness of breast cancer cells MDA-MB-231. J Cancer Res Clin Oncol 137: 1687-1696, 2011.

17. Wang J, Weng Y, Zhang M, Li Y, Fan M, Guo Y, Sun Y, $\mathrm{Li} \mathrm{W}$ and Shi Q: BMP9 inhibits the growth and migration of lung adenocarcinoma A549 cells in a bone marrow stromal cellderived microenvironment through the MAPK/ERK and NF-кB pathways. Oncol Rep 36: 410-418, 2016.

18. Thawani JP, Wang AC, Than KD, Lin CY, La Marca F and Park P: Bone morphogenetic proteins and cancer: Review of the literature. Neurosurgery 66: 233-246; discussion 246, 2010.

19. Shepherd TG and Nachtigal MW: Identification of a putative autocrine bone morphogenetic protein-signaling pathway in human ovarian surface epithelium and ovarian cancer cells. Endocrinology 144: 3306-3314, 2003.

20. Peng J, Yoshioka Y, Mandai M, Matsumura N, Baba T, Yamaguchi K, Hamanishi J, Kharma B, Murakami R, Abiko K, et al: The BMP signaling pathway leads to enhanced proliferation in serous ovarian cancer-A potential therapeutic target. Mol Carcinog 55: 335-345, 2016.

21. Peart TM, Correa RJ, Valdes YR, Dimattia GE and Shepherd TG: BMP signalling controls the malignant potentia of ascites-derived human epithelial ovarian cancer spheroids via AKT kinase activation. Clin Exp Metastasis 29: 293-313, 2012.

22. Chen C, Grzegorzewski KJ, Barash S, Zhao Q, Schneider H Wang Q, Singh M, Pukac L, Bell AC, Duan R, et al: An integrated functional genomics screening program reveals a role for BMP-9 in glucose homeostasis. Nat Biotechnol 21: 294-301, 2003.

23. David L, Mallet C, Keramidas M, Lamandé N, Gasc JM, Dupuis-Girod S, Plauchu H, Feige JJ and Bailly S: Bone morphogenetic protein-9 is a circulating vascular quiescence factor. Circ Res 102: 914-922, 2008

24. Herrera B, Dooley S and Breitkopf-Heinlein K: Potential roles of bone morphogenetic protein (BMP)-9 in human liver diseases. Int J Mol Sci 15: 5199-5220, 2014.

25. Ren W, Sun X, Wang K, Feng H, Liu Y, Fei C, Wan S, Wang W, Luo J, Shi Q, et al: BMP9 inhibits the bone metastasis of breast cancer cells by downregulating $\mathrm{CCN} 2$ (connective tissue growth factor, CTGF) expression. Mol Biol Rep 41: 1373-1383, 2014

26. Li Q, Gu X, Weng H, Ghafoory S, Liu Y, Feng T, Dzieran J, Li L, Ilkavets I, Kruithof-de Julio M, et al: Bone morphogenetic protein-9 induces epithelial to mesenchymal transition in hepatocellular carcinoma cells. Cancer Sci 104: 398-408, 2013.

27. Jung JW, Yoon SM, Kim S, Jeon YH, Yoon BH, Yang SG, Kim MK, Choe S and Kuo MM: Bone morphogenetic protein- 9 is a potent growth inhibitor of hepatocellular carcinoma and reduces the liver cancer stem cells population. Oncotarget 7: 73754-73768, 2016.
28. Sherma S and Lippard S: Structural aspects of platinum anticancer durg interaction with DNA. Chem Rev 87: 1153-1157, 1987.

29. Zhou K, Shi X, Huo J, Liu W, Yang D, Yang T, Qin T and Wang C: Bone morphogenetic protein 4 is overexpressed in and promotes migration and invasion of drug-resistant cancer cells. Int J Biol Macromol 101: 427-437, 2017.

30. Gao Y, Shan N, Zhao C, Wang Y, Xu F, Li J, Yu X, Gao L and Yi Z: LY2109761 enhances cisplatin antitumor activity in ovarian cancer cells. Int J Clin Exp Pathol 8: 4923-4932, 2015.

31. Hover LD, Young CD, Bhola NE, Wilson AJ, Khabele D, Hong CC, Moses HL and Owens P: Small molecule inhibitor of the bone morphogenetic protein pathway DMH1 reduces ovarian cancer cell growth. Cancer Lett 368: 79-87, 2015.

32. Lian WJ, Liu G, Liu YJ, Zhao ZW, Yi T and Zhou HY: Downregulation of BMP6 enhances cell proliferation and chemoresistance via activation of the ERK signaling pathway in breast cancer. Oncol Rep 30: 193-200, 2013.

33. Herrera B, van Dinther M, Ten Dijke P and Inman GJ: Autocrine bone morphogenetic protein-9 signals through activin receptor-like kinase-2/Smad1/Smad4 to promote ovarian cancer cell proliferation. Cancer Res 69: 9254-9262, 2009.

34. Brand V, Lehamann C, Umkehrer C, Thier M, de Wouters M, Raemsch R, Jucknischke U, Haas A, Breuer S: Impact of selective anti-BMP9 treatment on tumor cells and tumor angiogenesis. Mol Oncol 10: 1603-1620, 2016.

35. Kalluri R and Weinberg RA: The basics of epithelial-mesenchymal transition. J Clin Invest 119: 1420-1428, 2009.

36. Zhang L, Ye Y, Long X, Xiao P, Ren X and Yu J: BMP signaling and its paradoxical effects in tumorigenesis and dissemination. Oncotarget 7: 78206-78218, 2016.

37. Marcucci F, Stassi G and De Maria R: Epithelial-mesenchymal transition: A new target in anticancer drug discovery. Nat Rev Drug Discov 15: 311-325, 2016.

38. Rosso M, Majem B, Devis L, Lapyckyj L, Besso MJ, Llauradó M, Abascal MF, Matos ML, Lanau L, Castellví J, et al: E-cadherin: A determinant molecule associated with ovarian cancer progression, dissemination and aggressiveness. PLoS One 12: e0184439, 2017.

39. Miow QH, Tan TZ, Ye J, Lau JA, Yokomizo T, Thiery JP and Mori S: Epithelial-mesenchymal status renders differential responses to cisplatin in ovarian cancer. Oncogene 34: 1899-1907, 2015.

40. Chebouti I, Kasimir-Bauer S, Buderath P, Wimberger P, Hauch S, Kimmig R and Kuhlmann JD: EMT-like circulating tumor cells in ovarian cancer patients are enriched by platinum-based chemotherapy. Oncotarget 8: 48820-48831, 2017.

41. Shibue T and Weinberg RA: EMT, CSCs, and drug resistance: The mechanistic link and clinical implications. Nat Rev Clin Oncol 14: 611-629, 2017.

42. Vega S, Morales AV, Ocaña OH, Valdés F, Fabregat I and Nieto MA: Snail blocks the cell cycle and confers resistance to cell death. Genes Dev 18: 1131-1143, 2004.

43. Liang SQ, Marti TM, Dorn P, Froment L, Hall SR, Berezowska S, Kocher G, Schmid RA and Peng RW: Blocking the epithelial-to-mesenchymal transition pathway abrogates resistance to anti-folate chemotherapy in lung cancer. Cell Death Dis 6: e1824, 2015.

This work is licensed under a Creative Commons Attribution-NonCommercial-NoDerivatives 4.0 International (CC BY-NC-ND 4.0) License. 